\section{Human mesenchymal stem cells conditioned media promotes the wound healing process - An in vitro study}

\author{
Rashi K Jain ${ }^{1 *}$, Devashree Vakil ${ }^{1}$, Corey Cunningham ${ }^{1}$ and Kuldip \\ Sidhu', ${ }^{1,2}$ \\ ${ }^{1}$ CK Cell Technologies, Pty Ltd, Australia \\ ${ }^{2}$ Centre for Healthy Brain Ageing (CHeBA), Faculty of Medicine, University of New South Wales, Australia
}

\section{Abstract}

Mesenchymal stem cells (MSCs) conditioned medium (CM) has a promising prospect towards skin regeneration. Therefore, human dental pulp and adipose stem cells (DPSCs and ADSCs) were isolated, propagated and evaluated for their stemness and genetic stability over time in culture before making CM. We aimed to characterize the applicability of lyophilized ADSCs and DPSCs derived CM (AD-CM and DP-CM) at $5 \mathrm{mg}, 10 \mathrm{mg}$ and $20 \mathrm{mg}$ for wound healing process. The ability of wound closure was assessed by direct human dermal fibroblast cell scratch assay, treated with variable concentrations of AD-CM and DP-CM in vitro. Additionally, we also assessed the expression of different cytokines and growth factors secreted from ADSCs and DPSCs in the $\mathrm{CM}$ relevant to the wound healing by cytokine array analysis. Our data demonstrates a significant effect of both the AD-CM and DP-CM in wound healing within $24 \mathrm{hrs}$ compared to that in control.

\section{More Information}

*Address for Correspondence: Rashi Khanna Jain, CK Cell Technologies Pty Ltd, 20/9 Hudson Avenue Castle Hill NSW 2154, Australia, Tel: 0416486066; Email: rashi@ckcelltechnologies.com

Submitted: 29 October 2019

Approved: 07 November 2019

Published: 08 November 2019

How to cite this article: Jain RK, Vakil D, Cunningham C, Sidhu K. Human mesenchymal stem cells conditioned media promotes the wound healing process - An in vitro study. J Stem Cell Ther Transplant. 2019; 3: 028-030.

DOI: dx.doi.org/10.29328/journal.jsctt.1001016

Copyright: @ 2019 Jain RK, et al. This is an open access article distributed under the Creative Commons Attribution License, which permits unrestricted use, distribution, and reproduction in any medium, provided the original work is properly cited

Check for updates

\section{Introduction}

Skin wound healing is an organized process involving distant interplay of specialized cells for repair and regeneration [1]. Mesenchymal stem cells (MSCs) derived from dental pulp tissue and adipose tissue have been broadly studied for their stemness, regenerative potential and in treatment of various medical conditions [2-4]. More recently, MSCs derived conditioned media (MSC-CM) has been reported as a rich source of important growth factors and cytokines effective in wound healing and repair [5-7]. With the emergence of this approach, lyophilized growth factors and cytokines obtained from MSC-CM can be evaluated for safety, dosage and shelf life which brings them much closer to translational cell-free therapeutics.

Several studies, have widely used in vitro scratch assay for quantifying dermal fibroblast cells migration rate for wound repair, as it provides a simple and economical protocol [8]. Additionally, the most commonly used method to test the expression of the essential growth factors or cytokines in the conditioned media (CM) is through cytokine array analysis [9]. In this brief communication, we have evaluated the possibility of using lyophilized DP-CM or AD-CM at varying concentration such as $5 \mathrm{mg}, 10 \mathrm{mgs}$ and $20 \mathrm{mgs}$ as a promising alternative non-cellular approach to skin wound repair. Furthermore, we have highlighted the cytokines involved in migration, proliferation and angiogenesis essentially present in CM for wound healing.

\section{Materials and Methods \\ Study design and patient samples}

Third molar teeth from healthy individuals between the age of 18-25 years, were extracted with informed consent by the dentist and transferred to the lab in $10 \mathrm{ml}$ of sterile phosphate buffer solution. Human adipose tissue were extracted by liposuction technique with informed consent by surgeons and transferred to the lab for processing within an hour. The dental pulp stem cells (DPSCs) and adipose stem cells (ADSCs) derived from tissues were as per our patented technology (PCT/AU2019/051029) and same were used for preparation of conditioned media (CM).

\section{Conditioned media}

DPSCs and ADSCs from p-3 to p-5 were cultured in T75 tissue culture flasks in xenofree/serumfree (XF/SF) media (Miltenyi Biotec Bergisch Gladbach, Germany) at $37^{\circ} \mathrm{C}$ and $5 \%$ $\mathrm{CO}_{2}$ for harvesting conditioned media (CM). The confluency of the cultures at $75 \%-80 \%$ (3-5 days) was used as a criterion for 
starting the conditioning process. The supplement-containing media (Miltenyi Biotec, Bergisch Gladbach, Germany) was aspirated and the T75 flasks were rinsed twice with $5 \mathrm{~mL}$ prewarmed Phosphate Buffered saline (PBS) (Miltenyi Biotec, Bergisch Gladbach, Germany) to remove residual traces of supplement. Thereafter, $15 \mathrm{ml}$ of fresh GMP grade xenofree, serum-free, phenol red free and supplement-free media (Miltenyi Biotec, Bergisch Gladbach, Germany) was added to the T75 flask and incubated for $24 \mathrm{hrs}$ for conditioning at $37^{\circ} \mathrm{C}$ at $5 \% \mathrm{CO}_{2}$. The $\mathrm{AD}-\mathrm{CM}$ and $\mathrm{DP}-\mathrm{CM}$ was passed through a 0.45 $\mu \mathrm{m}$ filter and stored in $15 \mathrm{~mL}$ falcon tubes at $-80^{\circ} \mathrm{C}$. Thereafter, $\mathrm{CM}$ were lyophilized and stored at $+4^{\circ} \mathrm{C}$.

\section{Scratch wound assay}

The experiment was set up for both AD-CM and DP-CM at varying concentration such as $5 \mathrm{mg}, 10 \mathrm{mg}$ and $20 \mathrm{mg}$. The CHeBA's proprietary, HDF06 fibroblast cell line was used for the assay, 100,000 cells were plated per well on a 12 well culture plate, after $72 \mathrm{hrs}$, manual scratch was created using a tip of the sterile pipette. Following with two PBS washes, specific areas were marked at the bottom of the plate to take photos before the treatments. GMP grade Phenol red free (PRF) media (Miltenyi Biotec, Bergisch Gladbach, Germany) was used as control and $5 \mathrm{mg}, 10 \mathrm{mg}$ and $20 \mathrm{mg}$ of lyo AD-CM and DP-CM were reconstituted in $2 \mathrm{~mL}$ of PRF media and then added to the HDF06 cells for $24 \mathrm{hrs}$. After $24 \mathrm{hrs}$, the scratch was observed for gap closure and photos were taken at the same marked spot. The gap closure was analysed by using Image J software (https://imagej.nih.gov/ij/).

\section{Cytokine array analysis}

The lyophilised powder of DP-CM and AD-CM were weighed and reconstituted in $1 \mathrm{~mL}$ of reversed osmosis (RO) water. Cytokine array analysis was performed following the manufacturer's instructions (R\&D Systems, Inc., Minneapolis, USA). Briefly, after blocking the membranes with array buffer 6 for one hour, $775 \mathrm{uL}$ of DP-CM and ADCM was mixed with $725 \mathrm{uL}$ array buffer 6 and added to the membranes for an overnight incubation at $4^{\circ} \mathrm{C}$ on a shaker. Next day, the membranes were washed and treated with the specific buffers as per instructions by the manufacturer. The membranes were exposed by using chemiluminescence (FUJI LAS3000 Gel documentation system and LAS3000 software). Analysis of the membranes were performed using the Array analyser using the Image J software (https://imagej.nih.gov/ ij/). The background intensity of the negative control spots was subtracted from the sample values to obtain normalized densitometry values.

\section{Statistical analysis}

The statistical analyses of the results were performed with Graph Pad Prism 8. The data are presented as mean \pm standard deviation (SD) and experiments were carried out in triplicates. All statistical analyses were performed at the significance level $p<0.05$ using three-way analysis of variance (ANOVA) for multiple comparisons.

\section{Results and Discussion}

The application of adipose and dental pulp tissue-derived stem cells has been studied extensively and they represent a promising source for cell or cell-free therapeutics $[3,4,10,11]$. In this communication, we have briefly highlighted the potential of DP-CM and AD-CM as a cell-free therapy for wound repair and regeneration. Our data suggest that $\mathrm{AD}-\mathrm{CM}$ and DP-CM comprised of several essential growth factors and cytokines for wound repair. Additionally, we can emphasize here that mass-production of lyophilized CM is possible under controlled laboratory conditions for therapies.

Over time the traditional scratch assay has been used to evaluate the wound healing by gap closure in vitro, our data shows that both the lyophilized AD-CM and DP-CM at 10 mgs and $20 \mathrm{mg}$ concentration resulted in closure of the gap at 24 hour time point (Figures 1,2). However, scratch assay has its own limitation in the protocol for creating scratches proceeding to inter-lab variance $[8,12]$. To further substantiate the relevance of our study we have analyzed the expression of essential growth factors involved in wound repair in $\mathrm{CM}$ (Figure 3).

It has been widely reported that Serpin E1, HGF and bFGF plays an important role in re-epithelialization, granulation tissue formation and increases fibroblast proliferation [13]. The role of MSCs in angiogenesis is of great interest since inadequate vessel growth leads to wound healing disorders

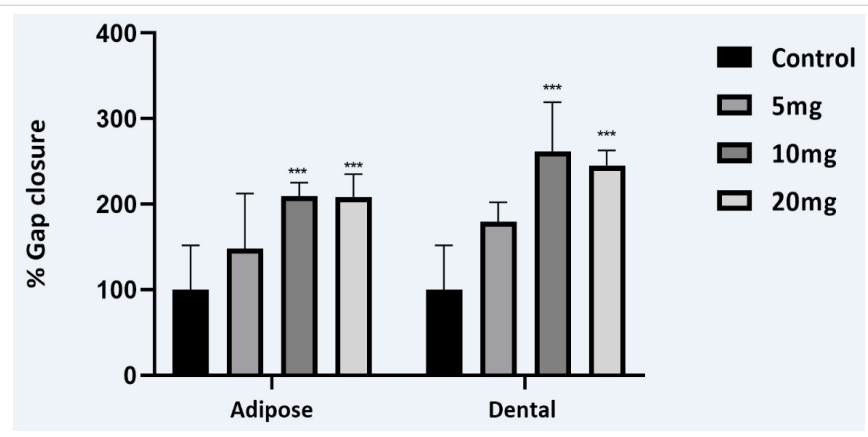

Figure 1: The dose response of lyophilised DP-CM and AD-CM in scratch wound assay representing significant percentage gap closure that corresponds to the distance migrated by the human dermal fibroblast cells.
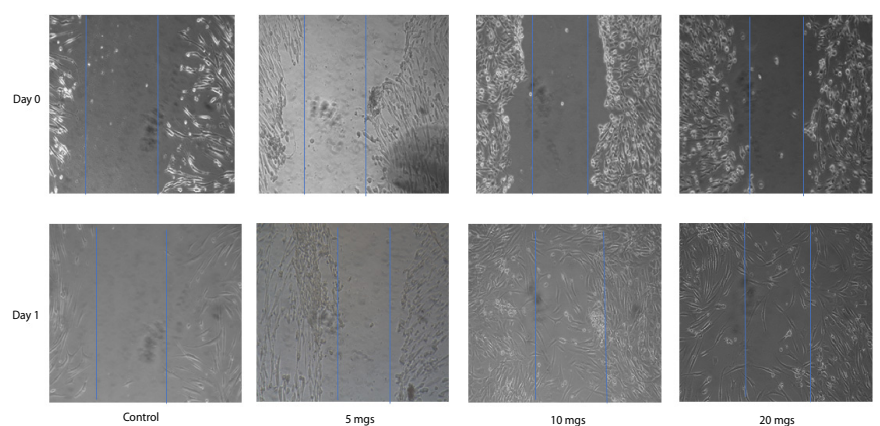

Figure 2: A representative scratch wound assay images, showing the migration of human dermal fibroblast cells treated with $5 \mathrm{mgs}, 10 \mathrm{mgs}$ and $20 \mathrm{mgs}$ DP-CM in comparison to the control at 0 hrs and $24 \mathrm{hrs}$. 


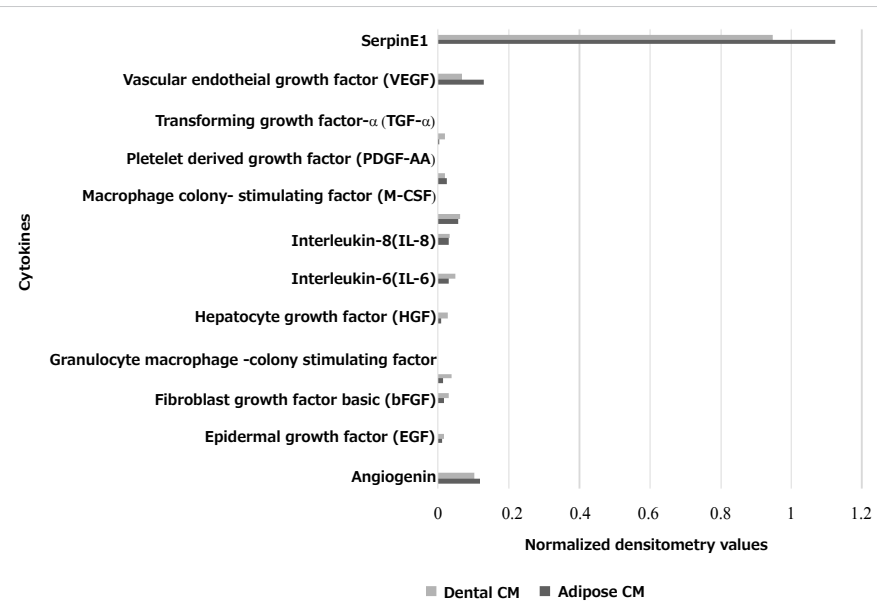

Figure 3: Cytokine array analysis showing normalized densitometry values of the cytokines secreted by AD-CM and DP-CM that are important for wound healing.

Table 1: Functions of important cytokines relevant to the wound healing of the total 105 assessed and secreted by adipose and dental mesenchymal stem cells

\begin{tabular}{|c|c|}
\hline Cytokines secreted in the CM & Function \\
\hline Angiogenin & Vasculogenesis \\
\hline Epidermal growth factor (EGF) & Proliferation of fibroblast \\
\hline Fibroblast growth factor basic (bFGF) & $\begin{array}{c}\text { Fibroblast proliferation and matrix } \\
\text { deposition }\end{array}$ \\
\hline $\begin{array}{c}\text { Granulocyte macrophage -colony stimulating } \\
\text { factor (GM-CSF) }\end{array}$ & Proliferation of epidermal cells \\
\hline Hepatocyte growth factor (HGF) & Granulation tissue formation \\
\hline Interleukin-6 (IL-6) & Re-epithelialisation \\
\hline Interleukin-8 (IL-8) & Re-epithelialisation \\
\hline Macrophage colony-stimulating factor \\
(M-CSF) & Stem cell progenitor cells support \\
\hline Platelet derived growth factor (PDGF-AA) & Cells migration \\
\hline Transforming growth factor-a (TGF-a) & Early phase reepithelialisation \\
\hline Vascular endothelial growth factor (VEGF) & Regulator for vasculogenesis \\
SerpinE1 & Cells migration \\
\hline
\end{tabular}

[9]. The importance of Angiogenin, VEGF, EGF, HGF, TGF- $\alpha$ and IL-8 or IL-6 (Table 1) for endothelial survival, migration and proliferation has been reported by many studies $[12,14,15]$. Collectively, these essential growth factors were sufficiently expressed and suggests the potential applicability of the DP$\mathrm{CM}$ and $\mathrm{AD}-\mathrm{CM}$ in wound healing. Further studies on animal models and also the clinical trials are required to substantiate the data.

\section{Acknowledgment}

The human fibroblasts HDF06 were obtained with informed consent from UNSW (HREC approval \# HC-15025), The Centre of Healthy Brain Ageing, University of New South Wales, Australia for this study.

\section{References}

1. Su L, Zheng J, Wang $Y$, Zhang $W$, Hu D. Emerging progress on the mechanism and technology in wound repair. Biomed Pharmacother. 2019; 117: 109191.

PubMed: https://www.ncbi.nlm.nih.gov/pubmed/31387187
2. Jin Q, Yuan K, Lin W, Niu C, Ma R. Comparative characterization of mesenchymal stem cells from human dental pulp and adipose tissue for bone regeneration potential. Artif Cells Nanomed Biotechnol. 2019; 47: 1577-1584.

PubMed: https://www.ncbi.nlm.nih.gov/pubmed/31027424

3. Marei MK, El Backly RM. Dental Mesenchymal Stem Cell-Based Translational Regenerative Dentistry: From Artificial to Biological Replacement. Front Bioeng Biotechnol. 2018; 6: 49.

PubMed: https://www.ncbi.nlm.nih.gov/pmc/articles/PMC5941981/

4. Shingyochi $\mathrm{Y}$, Orbay $\mathrm{H}$, Mizuno $\mathrm{H}$. Adipose-derived stem cells for wound repair and regeneration. Expert Opin Biol Ther. 2015; 15: 1285-1292. PubMed: https://www.ncbi.nlm.nih.gov/pubmed/26037027

5. Hocking AM, Gibran NS. 2010. Mesenchymal stem cells: paracrine signaling and differentiation during cutaneous wound repair. Exp Cell Res. 2010; 316: 2213-2219.

PubMed: https://www.ncbi.nlm.nih.gov/pubmed/20471978

6. Jayaraman P, Nathan P, Vasanthan P, Musa S, Govindasamy V. Stem cells conditioned medium: a new approach to skin wound healing management. Cell Biol Int. 2013; 37: 1122-1128.

PubMed: https://www.ncbi.nlm.nih.gov/pubmed/23716460

7. Sagaradze G, Grigorieva O, Nimiritsky P, Basalova N, Kalinina N, et al. Conditioned Medium from Human Mesenchymal Stromal Cells: Towards the Clinical Translation. Int J Mol Sci. 2019; 20. PubMed: https://www.ncbi.nlm.nih.gov/pmc/articles/PMC6479925/

8. Liang CC, Park AY, Guan JL. In vitro scratch assay: a convenient and inexpensive method for analysis of cell migration in vitro. Nat Protoc. 2007; 2: 329-333.

PubMed: https://www.ncbi.nlm.nih.gov/pubmed/17406593

9. Vizoso FJ, Eiro N, Cid S, Schneider J, Perez-Fernandez R. Mesenchymal Stem Cell Secretome: Toward Cell-Free Therapeutic Strategies in Regenerative Medicine. Int J Mol Sci. 2017; 18. PubMed: https://www.ncbi.nlm.nih.gov/pubmed/28841158

10. Kim JH, Jung M, Kim HS, Kim YM, Choi EH. Adipose-derived stem cells as a new therapeutic modality for ageing skin. Exp Dermatol. 2011; 20: 383-387.

PubMed: https://www.ncbi.nlm.nih.gov/pubmed/21355887

11. Mendicino M, Bailey AM, Wonnacott K, Puri RK, Bauer SR. MSC-based product characterization for clinical trials: an FDA perspective. Cell Stem Cell. 2014: 14: 141-145.

PubMed: https://www.ncbi.nlm.nih.gov/pubmed/24506881

12. Park JW, Hwang SR, Yoon IS. Advanced Growth Factor Delivery Systems in Wound Management and Skin Regeneration. Molecules. 2017; 27: 22. PubMed: https://www.ncbi.nlm.nih.gov/pubmed/28749427

13. Simone TM, Longmate WM, Law BK, Higgins PJ. Targeted Inhibition of PAl-1 Activity Impairs Epithelial Migration and Wound Closure Following Cutaneous Injury. Adv Wound Care (New Rochelle). 2015; 1;4: 321-328.

PubMed: https://www.ncbi.nlm.nih.gov/pmc/articles/PMC4440983/

14. Tello-Montoliu A, Patel JV, Lip GY. Angiogenin: a review of the pathophysiology and potential clinical applications. J Thromb Haemost. 2006; 4: 1864-1874.

PubMed: https://www.ncbi.nlm.nih.gov/pubmed/16961595

15. Werner S, Grose R. Regulation of wound healing by growth factors and cytokines. Physiol Rev. 2003; 83: 835-870.

PubMed: https://www.ncbi.nlm.nih.gov/pubmed/12843410 